\title{
A conceptual framework for digital civics pedagogy informed by the philosophy of information
}

Estelle Clements

Technological University Dublin, digitalcivics@gmail.com

Follow this and additional works at: https://arrow.tudublin.ie/aaschmedart

Part of the Social and Philosophical Foundations of Education Commons

\section{Recommended Citation}

Clements, E. (2020), "A conceptual framework for digital civics pedagogy informed by the philosophy of information", Journal of Documentation, Vol. 76 No. 2, pp. 571-585. https://doi.org/10.1108/

JD-07-2019-0139

This Article is brought to you for free and open access by the School of Media at ARROW@TU Dublin. It has been accepted for inclusion in Articles by an authorized administrator of ARROW@TU Dublin. For more information, please contact arrow.admin@tudublin.ie, aisling.coyne@tudublin.ie,gerard.connolly@tudublin.ie.

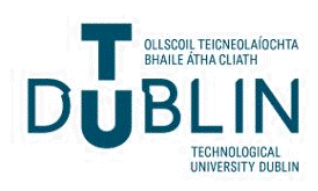




\title{
A conceptual framework for digital civics pedagogy informed by the philosophy of information
}

Digital civics pedagogy

\author{
Estelle Clements \\ Dublin Institute of Technology, Dublin, Ireland
}

\begin{abstract}
Purpose - The purpose of this paper is to draw on the philosophy of information, specifically the work of Luciano Floridi, to argue that digital civics must fully comprehend the implications of the digital environment, and consequently an informational ontology, to deliver to students an education that will prepare them for full participation as citizens in the infosphere.

Design/methodology/approach - Introducing this philosophy for use in education, the research discusses the ethical implications of ontological change in the digital age; informational organisms and their interconnectivity; and concepts of agency, both organic and artificial in digitally mediated civic interactions and civic education.
\end{abstract}

Findings - With the provision of a structural framework rooted in the philosophy of information, robust mechanisms for civics initiatives can be enacted.

Originality/value - The paper allows policy makers and practitioners to formulate healthy responses to digital age challenges in civics and civics education.

Keywords Philosophy of information, Educational philosophy, Civics education, Digital civics,

Digital teaching and learning, Information ethics

Paper type Research paper

\section{Digital civics and Floridi's Philosophy of Information}

Digital civics refers to civic behaviours, citizenship or democratic engagement in the digital realm, encompassing various dimensions of ethical and responsible behaviour in digital age contexts. It takes account of the ubiquitous inter-relationship between humanity and digital technologies, and the impact of this relationship on civic understanding and practise. This paper adopts the definition put forward in previous work undertaken by the researcher since 2010[1] presenting digital civics as: the study of the rights and responsibilities of citizens who inhabit the infosphere and access the world digitally. This incorporates an understanding of the environment within which civic actions take place and the basic rights and ethical responsibilities of citizens in traditional civics. The environment articulated in this definition, the infosphere, is underpinned by Luciano Floridi's Philosophy of Information (Floridi, 2002); a field that considers the use of computers and the philosophical issues that arise from them. This includes ethical issues as well as changes in self-understanding that result in behavioural changes or challenges. This complex philosophical underpinning, and its implications on civic behaviour and education will be explored in this paper. Digital civics is currently establishing currency as a term; however, this paper argues that an appropriate philosophical underpinning is critical to the success of digital civics and digital citizenship education initiatives. It further proposes that a broader knowledge of Floridi's presentation of the philosophy of information in education and related policy areas could promote an even greater sense of digital civic responsibility and pedagogical success in this area. Digital civics pedagogy requires a theoretically informed ethical framework cognisant of the informational environment in which ethical interactions occur, in order to successfully establish itself. To underpin this framework, this paper adopts as its starting point a digital ethics perspective informed by the work of 
JD

76,2

Charles Ess and Luciano Floridi, who ground notions of digital media ethics in the philosophy of information. This paper will outline Luciano Floridi's Philosophy of Information as a fundamental starting point for understanding the greater environment of the digital age, and the interactions that occur within it. While relating Floridi's philosophical ideas, it will identify areas of digital or civic education that are impacted or influenced by this environment, in order to tailor this theoretical framework to the needs of pedagogy. Finally, I will theorise a conceptual model, underpinned by Floridi's Philosophy of Information that proposes a starting place to open discussion on the development of digital civics pedagogy.

A philosophical investigation to underpin digital age education is necessary because digital convergence and the digital age have produced such major transformation: the "information turn" and its implications on human self-understanding, particularly of an ontological nature, raise important questions as to how behaviour, and specific to this work, ethical behaviour, will be affected. As Floridi states: "The information revolution is not about extending ourselves, but about re-interpreting who we are" (Floridi, 2008a, p. 6). The convergence present in the digital age produces philosophical implications that should be considered in forming educational methods. As Floridi puts it: "we will be in serious trouble, if we do not take seriously the fact that we are constructing the new environment that will be inhabited by future generations" (Floridi, 2007, p. 8).

In order to underpin the educational approach to digital civics framed in this research comprehensively, it is necessary to explore its conceptual foundation. Consequently I explore three key themes in Floridi's thought on information philosophy to understand the ways in which digital civic behaviour must be conducted responsibly and ethically for the good of the individual and society:

(1) the nature of the digital environment in which behaviour takes place (the "infosphere", or the nature of the abstract dephysicalised environment and the relationship between ethics and ontology);

(2) how behaviour in the digital environment is understood as an integrated part of the human (Floridi's "inforgs" and their interconnectivity); and

(3) the ways in which the digital mediates our civic behaviours resulting in unique forms of civic expression not previously possible (concepts of agency, both organic and artificial).

I begin by exploring the philosophy of information itself, which provides the grounding for the description of the "infosphere" (explained below) foundational to understanding the environment in which a student's civic and ethical behaviours in educational and online contexts take place.

\section{The philosophy of information}

The use of computers and the philosophical issues that arise from them are concerns dealt with in PI (Floridi, 2002, p. 137). Thus, PI offers a useful theoretical and philosophical framework as it is concerned with many of the same problems raised by this educational research. The philosophy is not entirely without criticism, for example, Harnad (2011), Capurro (2008) and Searle (2014) have all raised points of disagreement, but such criticisms seem to be in the minority. Floridi's work is already employed by digital education ethicists (such as Charles Ess), which makes it a useful and precedented approach from which to draw. Its function as an underpinning is similarly precedented, as Bawden and Robinson identify its value as a foundation for Library and Information Science (Bawden and Robinson, 2018). Floridi's work has also formed an important part of policy initiatives regarding ICTs. His work chairing the Onlife Initiative[2] for the European Commission, for instance, further denotes his distinction within the field and relevance to an important and developing aspect of public policy. 
Challenges arising from the world of information in educational environments include things such as the ubiquity of information, and the inefficacy of banning information technologies, for instance. The potential impact on educational philosophy should lead to new educational models that demonstrate the convergence inherent to the infosphere; a contribution only possible through consideration of the underlying philosophical premises of daily life in the infosphere.

As Floridi puts it, the "information turn", has caused a transition in the way humanity views itself and its environment (Floridi, 2002, p. 140, 2009a). The civic environment for which students were once prepared to participate has now altered so vastly that innovative approaches are necessary to prepare students for the world in which they will one day live, and indeed in which they already live. PI provides a theoretical framework within which questions can be posed; considering the relationship between our digital/informational world, ourselves and our interactions; speculating on the potential challenges of these interactions; and proposing potential outcomes and resolutions. These outcomes and resolutions can then be addressed in a practical sense of pedagogical implementation, however it is first necessary to consider the theoretical framework that will inform such pedagogy, in order to ensure its success. To accomplish this, it is useful to next comment on Floridi's presentation of the fourth revolution, as it provides an opportunity to assess the extent of change and impact communications technology and computeristation have precipitated on society and human behaviour.

\section{Floridi and the fourth revolution: understanding our changing world}

We are experiencing what may be described as a fourth revolution, in the process of dislocation and reassessment of humanity's fundamental nature and role in the universe. (Floridi, 2012, p. 10)

Such changes as those described by Floridi emerge when a philosophical dissonance provokes the need for a new perception of reality: for example, when scientific discovery presents data contrary to accepted belief. There is something Derridean in this philosophy that helps Floridi's Philosophy of Information consolidate well with media education scholarship. Derrida's notion of "free play", in which the centric position of the human is philosophically displaced through the exploration of meaning (Derrida, 1970), complements Floridi's philosophy and makes Derrida's work a useful bridge between Floridi's ideas on the "fourth revolution" and the meaning-making scholarship of foundational media education authors such as Marshall McLuhan - a figure with whom media educators are more likely to be familiar, given his role in formulating much of the early media literacy curriculum in North America. (Providing such bridges and links between Floridi's philosophical ideas, and familiar, trusted education theorists is pragmatic to foster understanding for teachers as to how Floridi might fit into their current framework of digital media education, and how they might make sense of new and complex ideas in PI.)

Floridi also suggests that this process has taken time to occur (Floridi, 2009a, p. 3). Thus, in contrast to suggestions that the current information age is a new development, by scholars such as Castells (1996, 1997, 1998), Floridi argues it has taken approximately 6,000 years for information society to unfold (Floridi, 2007, 2009a, p. 3). To lend further support to Floridi, arguments in classical history also discuss this philosophical process of the dislocation and reassessment of humanity's fundamental role in the universe and the subsequent changes it causes to self-understanding. For instance, the classical scholar David Ulansey notes extraordinarily similar parallels in exploring the late Hellenistic period with the modern digital age (Ulansey, 2000) to those observed by Floridi (especially in regard to the philosophical reassessment of humanity precipitated by scientific knowledge presented by Plato). This suggests that knowledge of historical antecedents 
JD

76,2 would be helpful for digital civics education, to situate it within a broader understanding of where our ideas originate, and how they might impact us as they unfold over time.

The fourth revolution can be understood through examination of its various aspects: the entire environment in which humans exist and interact (the infosphere); humanity's identity and role within this environment (as inforgs); and other types of agency within the infosphere (artificial agents); finally, this can raise questions as to the effect of these aspects on the exercising of civic powers. By doing so, I seek to construct a lens through which to explore the issues raised by digital technologies on civics, and to consider how these challenges might be addressed in pedagogy, and specifically pedagogy pertaining to civics and ethics.

The focus on what are clearly ontological elements in the discussion of the infosphere and even the inforg is a necessary basis for ethical discourse. There is a strong relationship between ethics and ontology (Long, 2004, p. 8). Ethical questions require an ontological consideration, one which can be taken account of, usefully, through Floridi's work on the infosphere. Thus, when Floridi and Sanders observe the re-ontologising and the "ontological friction" that is occurring as a result of ICTs, the consequences they list are ethical in nature:

[...] ICTs are well-known for being among the most influential factors that affect the ontological friction in the infosphere [...] significant consequences are [...] we shall witness a steady increase in agents' responsibilities. ICTs are making humanity increasingly accountable morally speaking, for the way the world is, will and should be. (Floridi and Sanders, 2001, p. 5)

Effectively, ethics and the nature of responsibility take on new dimensions as a result of ontological change. Because the strong relationship between ontology and ethics has considerable bearing on the formation of philosophies in the digital age, the development of educational responses to the digital age, such as digital civics, must take this relationship into account.

What form the necessary ethical formation might take in these circumstances is contested. Scholars such as Charles Ess and Shannon Vallor have argued for a formulation of virtue ethics. Floridi has disagreed, suggesting that while "the essentially constructionist lesson taught by virtue ethics [...] is more important than ever before", its emphasis on the individual agent renders it "intrinsically egopoietic" (Floridi, 2013, p. 164): that its inadequacy to address the responsibilities of the individual agent to the surrounding community or environment can lead to relativism and moral escapism.

Virtue ethicists have countered this claim by suggesting a formulation of virtue ethics that incorporates the ethics of care (which involves virtues such as care, benevolence and empathy in the process of ethical decision making and acting) (Gilligan, 1982). The works of Shannon Vallor (2016) and Charles Ess (2011) employ the philosophy of information while advocating for a formulation of virtue ethics that emphasises the importance of virtues including empathy. They also assert the usefulness of the component of Phronesis (Practical wisdom) in virtue ethics for its ability to direct, modulate and integrate "the enactments of a person's individual moral virtues [...] to the unique demands of each situation" (Vallor, 2016, p. 19), making it a useful and flexible formulation to deal with various challenges. Such research has further sought to ease the tensions between individual and social responsibilities in relation to "other" through a formulation called "hybrid selves"(Ess and Fossheim, 2013, p. 46; Ess, 2010b, p. 116, 2011, p. 20): an approach that conjoins individual and relational selfhood, intended to "sustain high modern ethical norms and political commitments" (Ess and Fossheim, 2013, p. 50). This is already a useful tool in formulating digital age ethical responses to challenges where the individual and community must reconcile different approaches or beliefs; such as when navigating the treatment of personal data in public contexts, a current challenge in information privacy (Nissenbaum, 2010). This concept of hybrid selves highlights a further consequence of our changing ontology, our conceptions of civics, the rights and responsibilities we have to ourselves and 
others, alter, or present themselves in new and different ways. Consequently, digital civics education must contend with the ways in which our concepts of civics are remade by these ontological changes. Digital civics cannot merely be about the application of technology to civics, rather it must appreciate how our concepts of civics are refashioned for the digital age, in light of the fourth revolution.

Simply put, when we consider the impact of the fourth revolution, our technological advancements and subsequent changes in ontology have transformed our: philosophical understanding; ethical behaviours; and civic responsibilities, building over a long historical course. This suggests that understanding digital civics, and its education, requires an awareness of a philosophy suited to making sense of life in the digital age (the philosophy of information); an appreciation for the way in which this impacts our treatment and behaviour of others (ethics); the way in which this remakes our ideas about fundamental civic rights and responsibilities (civics); and awareness of the precursors that lay the foundations upon which we have built our ideas over time (history). Such an approach, which encourages students to engage with conceptual ideas, provides a firm grounding for students to make sense of their changing world. It also assists them in understanding some of the "cognitive biases" that play a role in shaping their opinions and behaviours - an important aspect of potential political information education observed by Smith and McMenemy (2017) in relation to psychological perspective.

\section{The infosphere: understanding our informational selves}

The infosphere is an umbrella term, representing the complete environment in which we live (Floridi, 1999), including information entities (such as humans) and their interactions and processes within the digital and analogue worlds as ecosystems within this greater environment. Floridi observes that reality can be viewed as informational, and the digital environment (which fully encompasses the world around us as it mediates our interactions) is helping humans to create a more informational ontology. There are important consequences for educators in the clear and valuable distinction Floridi draws between a digital ontology and an informational one. For Floridi, a digital ontology, in which the nature of reality is digital rather than analogue, differs from an informational ontology, in which the nature of reality is informational and the digital and analogue are simply differing levels of abstraction (LoA) through which we access and interpret reality, rather than ontologies themselves (see Floridi, 2008b, 2009b, p. 35). Viewing analogue and digital perceptions as equal, in that they are both means to understanding the world and greater reality, is of greater use than suggesting a hierarchical view of digital superiority because it is reality. Appreciating this distinction allows for discussion on the integration of digital tools into the educational environment without suggesting that they are the only means of education, or that they inherently provide a lesson by virtue of being digital. Putting an interactive whiteboard in a classroom does not equate to digital pedagogy if it continues to be used as an analogue tool (i.e. a chalkboard), and the possibilities it presents are ignored. The mere presence of digital technology in a classroom is not digital pedagogy; the digital pedagogy arrives in the way pedagogy is remade with the shift in thinking that takes place (similarly to the way that digital civics is not the application of technology to civics, but rather the way in which civics is remade by a shift in our thinking). In a 2014 interview with Forbes, Bob Harrison related how the very source of the problem with school's approaches to digital technology was their traditional teaching methods (Morrison, 2014). This is echoed by research coordinated by the OECD, on ICTs and learning, which recognises that "the real contributions ICT can make to teaching and learning have yet to be fully realised and exploited" (OECD, 2015, p. 15). It further suggests the need "to provide educators with learning environments that support 21st-century pedagogies and provide children with the 21st-century skills they need to succeed in tomorrow's world" (OECD, 2015). Digital civics
pedagogy 
JD

76,2

Thought for such environments is particularly pertinent, as the division between the digital and analogue blurs (Floridi, 2007, p. 6), and our perception of the world in which we live is increasingly accessed through the online, non-physical digital environment as opposed to the offline, physical analogue environment (which Floridi sometimes refers to as the Umwelt). For educators, a struggle is immediately apparent in that while the perception of reality held by many students is increasingly accessed via digital channels, the classroom environment expects students to access reality through physical means (or the Umwelt); this offline method of accessing reality in the formal classroom is increasingly foreign to students in the digital age (Jenkins, 2006a). Ideally then, a model of instruction should consolidate both offline and online experiences, creating a convergent environment that allows students to move between both LoA, merging information from both to form their learning experience: a transmediated process (Jenkins, 2006b). The educational potential of this has been explicitly theorised by Elwell (2014), Clements (2017) and Jenkins (2006b). Support for such an approach can also be garnered from Livingstone and Sefton-Green (2016), whose work recognises the importance of considering both the offline and online interactions contributing to an overall conception of teenage behaviour within school environments. A digital civics education initiative that fails to appreciate an informational ontology may fall victim to a false notion of dualism (suggesting a separation between the on and offline worlds). If teachers cannot make clear to students that the online and offline spheres are part of the same over-arching environment, then we cannot be surprised when students undertake compromising actions in one arena and fail to appreciate they will impact the other. This emphasises the importance of helping teachers and educational administrators understand and employ PI in their work, and the necessity of successfully incorporating transmedia environments into the contemporary classroom.

Finally, inhabiting Floridi's infosphere are informational entities, both organic (Floridi's "inforgs") and artificial (i.e. digital tools), whose existences are influencing and being influenced by each other digitally. To understand the changing landscape caused by the digital and examine the ways this may affect citizenship and consequently the pedagogy of civics, we will consider these next.

\section{Inforgs in the infosphere: managing our informational self}

As the infosphere has become increasingly accessed through the digitization, it has highlighted "the intrinsically informational nature of human agents" (Floridi, 2007, p. 10). Through a re-ontologisation of the environment and ourselves (Floridi, 2010b), humans exist as connected informational organisms, or inforgs (Floridi, 2007, p. 9). Existing as informational organisms, the ability to access and process digital information, that is, information literacy skills and digital literacy skills, become vital. Such a view has been shared broadly by digital education theorists such as: van Dijk and van Deursen (2014), Greene et al. (2014), Eshet-Alkalai (2004) and Gilster (1997). But the essential need for such literacies espoused by Floridi is not only to embolden participatory democracy, or to improve basic communication, rather it is because the management of information in a digital environment will become the critical means through which people navigate their very existence. "One day, being an inforg will be so natural that any disruption in our normal flow of information will make us sick. Even literally" (Floridi, 2007, p. 11). The notion of digital literacies as a set of "survival skills" espoused by the educational scholar Eshet-Alkalai takes on a greater imperative in this view, helping the human survive not only "a variety of obstacles and stumbling blocks" (Eshet-Alkalai, 2004, p. 103) but also as basic human requirements for life.

Traditional digital media literacy skills (such as understanding how to analyse content, make and remake content, communicate with others and participate in healthy ways in the community) and information literacy skills are assistive in formulating digital civics education initiatives if they are underpinned by the philosophy of information, but they are only part of digital civics education. Such endeavours should also include the other 
aforementioned areas that PI would suggest will also play a role in digital civics, that is: ethical skills, awareness of historical antecedents and the ways in which our notions of civics have been remade, in addition to an understanding of the fundamental concepts of PI. This focus on conceptual context is an idea that seems to sit well with Andersen's suggestion that "information literacy represents an understanding of society and its textual mediation” (Andersen, 2006, p. 226).

Other agents in the infosphere: managing our relationships with "other agents" The remaining group of agents to be observed inhabiting the infosphere are artificial agents. Digital tools (digital cameras, ipods, wireless networks and so forth) interact with humans and impact the infosphere, exercising their own agency. Floridi illustrates this relationship of inforg interacting with (both acting upon, and being acted upon) artificial agents through the example of an iPod and Nike shoes. The shoe feeds information about the runner's distance and pace to the iPod, which then provides music to suit the runner's pace, or motivate a change in it, in a feedback loop (Floridi, 2007, p. 7). Later generations of artificial companions are expected to become "more autonomous, and hence behave in self-initiated, self-regulated, goal-oriented ways and to be able to learn from their users in the machine learning sense of the expression" (Wilks, 2007, in Floridi, 2008a, p. 3). Imagine a gym class in which the instructor employs such a technology, helping each student to attain a personal best; or one in which the technology itself is the instructor? (Much like the educational feedback systems utilised in digital video gaming,[3] or language education software such as Rosetta Stone.) The activity of non-human agency in the infosphere raises issues of moral obligation and responsibility, placing even greater responsibility on the human, and upon educators and educational administrators (Floridi, 2007). Thus, successful civic participation in the infosphere will require robust ethical discourse and self-regulation on behalf of citizens (Ohler et al., 2015), and familiarity and engagement with the technologies mediating that participation (Jenkins, 2006a). To teach digital civics successfully, students and educators must have access to the tools and technologies that permeate the digital environment to be able to take account of these technologies and scaffold students to formulate healthy civic responses to, and coping strategies for, them.

\section{The online and offline: managing our connection to the flow of information}

Part of understanding the infosphere is concerned with understanding the dynamic relationship between the online and offline. Initially, when first popularised, the online world was viewed as a space confined to the world behind the screen of a computer. Interfacing with the online environment required the expenditure of a great deal of time and effort (from entering codes to suffering dial-up connections) that yielded a unique environment for communication. While the complications of accessing this environment sometimes deterred educators from using the technology, there were also advantages. Great distances could be traversed and new contacts made outside of local interactions. For teaching purposes, this could enable "connecting with classrooms in other communities and countries" (OCT, 2011).

In this scenario, the offline world was the "real" world - or rather, reality was perceived through the offline analogue environment. It was the setting in which people physically existed and "real" change was enacted, while the online one offered a sort of novel and emerging set of unexplored potentials. Eventually, the difficulties associated with accessing the digital world evaporated and information transfer became frictionless (Floridi, 2007, p. 5). The sudden and expansive influence of information connectivity in the educational environment led to numerous educational challenges (the "distracting" presence of mobile phones, or the pervasive presence of digital advertising, for example). Digital civics
pedagogy 
JD

76,2

As humanity's practise of information access changes from analogue to digital, highlighting the need for information connectivity, the realisation of the informational nature of humans and their environment becomes apparent. Realizing our informational nature, we view ourselves as inforgs and begin to understand an informational ontology; and educators need to take account of the consequences of an informational ontology, and how it impacts student's lives. For instance, the ability to effortlessly consume, process, create and transfer information has resulted in an increased interest in and even need for continual connection with the flow of information. As we begin to realise that we spend most of our time connected to the flow of digital information, a false boundary can no longer be placed separating the two LoA. "As digital immigrants like us are replaced by digital natives like our children, the latter will come to appreciate that there is no ontological difference between infosphere and Umwelt, only a difference in levels of abstraction" (Floridi and Sanders, 2004, cited in Floridi, 2007, p. 11).

The implications of such reliance on connection to the infosphere on the current formal school environment and teaching of civics are obvious. In the first instance, schools that operate in a disconnected fashion (e.g. by prohibiting the use of digital devices by students) are removing students from the information connectivity through which they access what is their perceived reality. Such a move will one day be tantamount to removing a fish from water: it cannot survive outside its environment (Floridi, 2007, p. 11). Thus the banning of technologies and digital convergence in schools can only serve as a temporary measure. To remove the means to interface with the reality in which humans exist will not be possible. Schools will need to find other ways of dealing with the pervasiveness of information connectivity such as teaching responsible and appropriate use of digital devices, prioritising information consumption and good ethical behaviour. During lessons, students will need to intrinsically value their education and structured personal development over unstructured social interactions, which can take place at alternative times, and pay attention for their own benefit rather than because they are forced: they will need to regulate their own behaviour. Alternatively, students may rank a lesson on a topic they have heard repeatedly as no longer relevant and choose to answer a text that they may value as having greater priority. They may also come to view lessons in which teachers fail to communicate the relevance of a subject area as unnecessary and spend their time instead engaged in personal research via their own digital devices. Certainly, it is not outrageous to suggest that some students already do this. Thus, while the ability to assess information and think critically for themselves is important for student success (skills required in traditional digital and media literacy), skills to regulate their own behaviour and discern the best use of their time in the educational environment are also vital. With the classroom no longer able to insulate itself from the outside world, students require greater amounts of self-discipline and personal responsibility. Such skills are not gained without practise, and an environment that removes opportunity to develop such skills (such as one in which the potential temptations of digital devices are banned, alleviating responsibility from the student) does not prepare one for civic life in the infosphere.

\section{The non-physical environment: managing our life in the digital age}

Another aspect of the digital environment is its non-physical nature. The frictionless infosphere in the digital accessing of reality means that information is less affected by physical limits, including its ability to travel outside the confines of space; and to transfer ideas that are increasingly abstract. This makes it possible to interact with the environment in new ways, for instance, increasingly abstract ideas can be portrayed and developed in interactive ways.

While the physical world requires people to interact with their environment as it is, an increasingly digital environment is not similarly confined. We can adapt the world itself, 
or interact with worlds of our own devising. Communication can happen almost instantaneously at a destination (provided that destination itself is connected to the digital environment) and could also contain different types of information (such as video and audio), expressing concepts in a more abstract way (such as, for instance, a dynamic blueprint), and both the sender and receiver may interact with it simultaneously. As we develop more numerous and improved methods of transferring information through a variety of digital media "the physical world [...] undergoes a process of virtualisation and distancing in which even the most essential tools, the most dramatic experiences, or the most touching feelings [...] can be framed within virtual mediation” (Floridi, 2002, p. 130).

Consequently, as we access our perception of reality through the digital environment, we come to apply this knowledge in our lives by understanding our world as an informational one which trades in abstract ideas and is interactive because our perception of reality is not focussed on the physical but rather, the experiential; we understand our perception of reality through a different level of abstraction.

Imagine putting these consequences together to understand a civic concept, such as democratic protest. Let us say that a teenager takes an interest in a protest occurring in a foreign country. They may watch the protest on their mobile phone, or even open a video chat conversation with other protestors who are physically present at that location. Eventually, as information transfer improves, that picture and audio will sharpen. The image of the student projected there and the images of the protestors projected back will become increasingly lifelike, perhaps eventually they will be fully consuming like holographic projection. They may be able to hear all the audio information occurring there as clearly as if present. Eventually, they may be able to smell the place and even experience tactile sensations from that location through information transfer. They could experience all the sensations of being present at that event. Their mind and body interacting with other protestors, or the local government forces present to police the protest, through an advanced process of information transfer. So where is this student? At home? At the protest in a foreign country? Or simply existing within the informational as they access their perception of reality digitally?

The ability to communicate entire moments of experience in this way poses an enormous set of questions. Consider the legal logistics of such a situation: might government leaders pursue arrests for being there but not really being there? Force extraditions? Illegitimise the protest, suggesting it was the work of foreign actors? What about protests on global issues in which citizens would argue they are all affected, such as climate change? And given the increasing awareness of how foreign policies interact with one another, where do you draw the line of what constitutes a global issue?

Such instances are not as futuristic as one might think. The potential for students to take up such an approach for civic discourse is already apparent. For instance, survivors of the Parkland School shooting slid seamlessly between social media, traditional newsmedia and live events to build momentum and disseminate their platform for gun control. Their nationwide protest involved millions of people in sites located around the world (Carlsen and Patel, 2018). Or consider the app released by the Catalonian Independence group "Tsunami Democratic" that intermarries real time communication data for location with instructions for protest activities. Protestors can interact, warn of police forces, re-group, move and mobilise in different ways based on this responsive, interactive system. What is more, no one knows who devised this system, or whether those protestors running it are even physically present in the country while they orchestrate protests - they could easily be anywhere else in the world (Losada and Bailey, 2019). Their potential involvement as foreign actors has also been raised (Faus and Carreño, 2019).

How does our perception of foreign events change when we can experience what is happening for ourselves? Students can sympathise with one side or another, but because
Digital civics pedagogy 
JD

76,2

580

they may enter the process without the context of a location's history and culture, struggle to understand what they are experiencing, or what is really going on. How do educators prepare students to be able to contextualise, recognise and "unpack" the complexities and nuances of a civic situation that is intensely ethical, bound by cultural and historical antecedents, civically complicated by differing concepts of governance and shaped by new ideas and philosophical concepts? The answer, perhaps, is to provide students with the best possible grounding in these conceptual tools, with skills that can apply and grow with new circumstances: to encourage processes that will guide them to compassionate answers that appreciate the diverse ways in which the world works, and to avoid over-confidence in conclusions about what is right drawn solely from their perspective. In order to accomplish this, students need learning environments that mimic the infosphere experience, moving between LoA, where they can face and experiment with these experiences in a safe educational space. Just the sort of environments posited by Elwell (2014), Clements (2017) and Jenkins (2006b). Certainly, the budding potential for virtual reality, and indeed augmented reality, to provide such experiential learning in the classroom is already being explored (Merchant et al., 2014; Bujak et al., 2013; Wu et al., 2013). But they must have widespread uptake in schools to be effective.

\section{Personal identity: managing our personal information}

Such transmedia environments also allow students to raise and consider other factors resulting from digital-age transitions, such as impact on identity - a critical factor in the formation of developing citizens. Floridi's work makes clear two important issues that further speak to the importance of fostering philosophical and ethical enquiry as robust practises in digital civics education: privacy and data use and corporate issues in schools.

Floridi observes that in a dephysicalised world, personal identity is eroded, because people begin to feel they are typified individuals, mass produced and anonymous among other mass produced and anonymous abstract entities online (Floridi, 2009a). And respond to this de-personalisation by self-branding through blogs, Facebook, Myspace, YouTube or any number of information sites that allow the expression of personality (Floridi, 2009a, p. 11).

First, because personal information is viewed as an extension of the self (Floridi and Tavani, 2008 in Ess, 2009, p. 59), citizens are caught between the need for informational secrecy to protect themselves from information theft or fraud, while they are simultaneously required to make their information public in order to distinguish their individuality and present themselves as unique. The issue of private data, and responsible access and use of information is raised.

Second, if the erosion of personal identity makes "digital natives" (Prensky, 2001) seeking means of individual expression malleable to branding as Floridi suggests, then the consequences of corporate interests in schools should be broached.

Fiscally vulnerable schools often turn to corporate interests to make up funding shortages in exchange for access to the school environment, and Floridi's work can help schools better appreciate their position and the full picture of consequences in making these kinds of decisions. The intrusion of corporate interests in the school environment (Schor, 2004) with their capacity to shape school infrastructure, and the insights of Kenway and Bullen (2001) that "the commodity form has increasingly become central to the life of the young of the West, constructing their identities and relationships, their emotional and social worlds [...]" (Kenway and Bullen, 2001, p. 187) could mean that - in a world where personal identity is under threat and where the pervasiveness of information (including advertising) is continual, and where the educational norm presented to developing citizens equates consumerist information or branding with identity and social development - there is potential that citizens fervently seeking to identify their individuality and exhibit their distinctiveness may align themselves with easily available streams of information (such as products like Facebook, or streams of 
advertising) as opposed to those which seem more arduous to obtain (such as self-knowledge and philosophical enquiry). Making clear that brands, such as Facebook or YouTube, might be used as pedagogical tools for identity development, but should not be confused with identity itself, is an important distinction for educators to impart to students: by discussing the identified brand and providing a "transmediated experience" including interconnected live interaction activities. As the religion scholar J. Sage Elwell suggests:

Thus, the transmedia model serves as a helpful paradigm for understanding the nature of self-identity and self formation in this new liminal space by offering the conceptual architecture necessary for exploring and articulating its integrated, dispersed, episodic, and interactive narrative character. (Elwell, 2014, p. 243)

It is also critical to impart the value of personal data, and the actual cost of exchanging that personal data as a price to access popular digital services, and to cultivate awareness of the ways in which these brands may take and use personal data from students and citizens so as not to normalise a belief on the part of students "that others have a right to keep their behaviour under constant surveillance for marketing purposes - even at the cost of their own well being." (Boninger and Molnar, 2016, p. 3). Given the increasing use of social media platforms in young people's democratic engagement, it is necessary to ensure that young citizens are prepared to deal with the ways in which their civic life and democratic processes may be inextricably linked with the technologies and corporations that facilitate their daily interactions. Such instances highlight the nature of connectivity and behaviour while demonstrating the validity of Floridi's philosophy. In concluding this paper, I will present a conceptual model, based in Floridi's PI that suggests a direction that may be taken to incorporate ideas of PI into digital civics education.

\section{A conceptual framework for digital civics pedagogy}

In this paper, I have identified the philosophical rationale for digital civics and why it is necessary, responding to Floridi's concepts of infosphere and informational philosophy. I noted that the informational environment in which we exist and enact behaviours has specific characteristics, namely: the blurring of boundaries between the online and offline worlds, perpetual connectivity and interactivity. Consequently, I explored three key themes in Floridi's thought on the philosophy of information to understand the ways in which digital civic behaviour must be conducted responsibly and ethically for the good of the individual and society: the nature of the digital environment in which behaviour takes place; how behaviour in the digital environment is understood as an integrated part of the human; and the ways in which the digital mediates our civic behaviours resulting in unique forms of civic expression not previously possible.

If the aim of digital civics pedagogy is to foster ethically and civically responsible citizens in the infosphere, then to answer the challenge of twenty-first century citizenship education, students will need an awareness of the influences that impact their experience as digital age citizens, the skills to cope in their environment and opportunities to practice these skills.

Impacting factors on our lives resulting from our technological advancement include the fourth revolution, which in turn changes our ontology. This spurs changes in the way we view ourselves and interact with one another. Understanding digital civics, and its education, requires an awareness of a philosophy suited to making sense of life in the digital age (the philosophy of information), an appreciation for the way in which this impacts our treatment and behaviour to one another (ethics), the way in which this remakes our ideas about fundamental human rights and responsibilities (civics) and the precursors that lay the foundations upon which we have built our ideas over time (history). This suggests the need to develop these four conceptual resources that can underpin and guide student development and decision making (philosophy, ethics, civics and history) in order to navigate our relationships with ourselves and others.
Digital civics pedagogy

$-1$


JD

76,2

The infosphere helps us understand ourselves as informational entities through a transmediated environment, thus we also require tools to navigate information in the digital environment (digital and information literacy skills). We further need to appreciate the presence and impact of other agents in the infosphere (i.e. Digital tools) and practise our interactions with those. Our need for continued connection to the flow of information in this environment means that students will need to regulate their own behaviour (skills in self-discipline). And finally, the non-physical nature of the digital portion of the environment leads to a world that is increasingly interactive and trades in abstract ideas impacting civic interactions, and affecting privacy, relationships with corporate organisations and personal identity.

Designing a space could take many forms, but one would certainly be the creation of an experimental learning environment that takes Floridi's work into account: a transmediated laboratory for fostering digital civic experience that offers immersion in perpetually connected, interactive environments where the boundaries between the online and offline realms are blurred. Appropriate to an educational environment, crossover between LoA would occur whilst maintaining enough control of the immersive space to ensure the reasonable protection of students as they experiment through experiential practice. Perhaps a closed-circuit digital school environment with concurrent live action learning activities that allow students to cross seamlessly between LoA using the very devices that they carry with them every day, implemented through graduated levels of independence so that students can take time learning how to cope with their increasing requirements of self-discipline and responsibility. Thus, this paper suggests that as a starting point to explore digital civics education, students learn:

- The impacting forces on life in the infosphere: the fourth revolution and an informational ontology and how these forces change their lives and world.

- The necessary skills and awareness to manage in the infosphere including: four conceptual resources (philosophical, ethical, civic and historical); skills in digital literacy and information literacy; familiarity with digital tools; self-discipline; knowledge of the issues affecting our privacy, relationships to corporate organisations and personal identity.

- In a space to practice: a suitably developed transmediated educational environment where students can experiment and learn.

The fourth revolution is not a distant notion of what might manifest in the world of information connectivity, but rather a grounded observation with which educators must seriously engage if they are to construct meaningful educational experiences relevant and appropriate for life. Educational measures to engage with these philosophies should not be regarded as an eventual possibility for which to prepare, but rather as a present necessity critical to success and survival as a human race.

\section{Notes}

1. This refers to the collaborative work undertaken between Dublin City Libraries and the researcher known as the Oscar Wilde digital civics pedagogy project, which sought to explore and create viable and practical solutions for digital civics and its education in a variety of contexts. For more, please see: http://digitalcivics.org/digital-civics-pedagogy/

2. Floridi's contribution to the Onlife Initiative on Hyperhistory and the Philosophy of Information Policies: www.oapen.org/search?identifier $=1001971$

3. For example, there are orientation modules when new skills are introduced in a game that provide educational feedback to assist the player develop the necessary skills to proceed in the game. 


\section{References}

Andersen, J. (2006), "The public sphere and discursive activities: information literacy as sociopolitical skills", Journal of Documentation, Vol. 62 No. 2, pp. 213-228, doi: 10.1108/00220410610653307.

Bawden, D. and Robinson, L. (2018), "Curating the infosphere: Luciano Floridi's philosophy of information as the foundation for library and information science", Journal of Documentation, Vol. 74 No. 1, pp. 2-17, doi: 10.1108/JD-07-2017-0096.

Boninger, F. and Molnar, A. (2016), "Learning to be watched: surveillance culture at school - the Eighteenth Annual Report on Schoolhouse Commercializing Trends, 2014-2015”, National Education Policy Center, Commercialism is Education Research Unit, Boulder, CO.

Bujak, K., Radu, I., Catrambone, R., Macintyre, B., Zheng, R. and Golubski, G. (2013), “A psychological perspective on augmented reality in the mathematics classroom", Computers \& Education, Vol. 68, pp. 536-544, doi: 10.1016/j.compedu.2013.02.017.

Capurro, R. (2008), "On Floridi's metaphysical foundation of information ecology", Ethics and Information Technology, Vol. 10 Nos 2-3, pp. 167-173.

Carlsen, A. and Patel, J. (2018), "March for our lives: maps of the more than 800 protests around the world”, The New York Times, 22 March, available at: www.nytimes.com/interactive/2018/03/22/ us/politics/march-for-lives-demonstrations.html (accessed 26 November 2019).

Castells, M. (1996), The Information Age: Economy, Society and Culture, Vol. I, The rise of the Network Society, 2nd ed., Blackwell, Oxford.

Castells, M. (1997), The Information Age: Economy, Society and Culture, Vol. II, The Power of Identity, 2nd ed., Blackwell, Oxford.

Castells, M. (1998), The Information Age: Economy, Society and Culture, Vol. III, End of Millennium, 2nd ed., Blackwell, Oxford.

Clements, E. (2017), "Digital civics in pedagogy: a response to the challenges of digital convergence in the educational environment", doctoral thesis, DIT, Dublin, doi: 10.21427/D7J45F.

Derrida, J. (1970), "Structure, sign and play in the discourses of the human sciences", in Macksey, R. and Donato, E. (Eds), The Structuralist Controversy, Johns Hopkins University Press, Baltimore, pp. 247-265.

Elwell, J.S. (2014), "The transmediated self: life between the digital and the analog", Convergence: The International Journal of Research into New Media Technologies, Vol. 20 No. 2, pp. 233-249, doi: 10.1177/1354856513501423.

Eshet-Alkalai, Y. (2004), "Digital literacy: a conceptual framework for survival skills in the digital era", Journal of Educational Multimedia and Hypermedia, Vol. 13 No. 1, pp. 93-106.

Ess, C. (2009), Digital Media Ethics, Polity Press, Cambridge.

Ess, C. (2010b), "The embodied self in a digital age: possibilities, risks, and prospects for a pluralistic (democratic/liberal) future?”, Nordicom Information, Vol. 32 No. 2, pp. 105-118.

Ess, C. (2011), "Self, community, and ethics in digital mediatized worlds", in Ess, C. and Thorseth, M. (Eds), Trust and Virtual Worlds: Contemporary Perspectives, Peter Lang Publishing, New York, NY, pp. 3-30.

Ess, C. and Fossheim, H. (2013), "Personal data: changing selves, changing privacies", in Hildebrandt, M., O'Hara, K. and Waidner, M. (Eds), Digital Enlightenment Yearbook 2013: The Value of Personal Data, IOS Press, Amsterdam, pp. 40-55.

Faus, J. and Carreño, B. (2019), "Spain closes Catalan protest group website and probes riots", Reuters, available at: www.reuters.com/article/us-spain-politics-catalonia-tsunami-idUSKBN1WX1ZJ (accessed 26 November 2019).

Floridi, L. (1999), Philosophy and Computing: An Introduction, Routledge, London.

Floridi, L. (2002), "What is the philosophy of information”, Metaphilosophy, Vol. 33 Nos 1/2, pp. 123-145.

Floridi, L. (2007), "A look into the future impact of ICT on our lives", The Information Society, Vol. 23 No. 1, pp. 59-64.
Digital civics pedagogy 
JD

76,2

Floridi, L. (2008a), “Artificial intelligence's new frontier: artificial companions and the fourth revolution”, Metaphilosophy, Vol. 39 Nos 4-5, pp. 651-655.

Floridi, L. (2008b), “A defence of informational structural realism”, Synthese, Vol. 161 No. 2, pp. 219-253.

Floridi, L. (2009a), “The information society and its philosophy”, The Information Society, Vol. 25 No. 3, pp. 153-158.

Floridi, L. (2009b), “Against digital ontology”, Synthese, Vol. 168 No. 1, pp. 151-178.

Floridi, L. (2010b), Information - A Very Short Introduction, Oxford University Press, Oxford.

Floridi, L. (2012), "Turing's three philosophical lessons and the philosophy of information", Royal Society's Philosophical Transactions A, Vol. 370 No. 1971, pp. 3536-3542.

Floridi, L. (2013), The Ethics of Information, Oxford University Press, Oxford.

Floridi, L. and Sanders, J. (2001), "Artificial evil and the foundation of computer ethics", Ethics and Information Technology, Vol. 3 No. 1, pp. 55-66.

Gilligan, C. (1982), In A Different Voice, Harvard University Press, Cambridge.

Gilster, P. (1997), Digital Literacy, Wiley Computer Publishing, New York, NY.

Greene, J., Yu, S. and Copeland, D. (2014), "Measuring critical components of digital literacy and their relationships with learning”, Computers \& Education, Vol. 76, pp. 55-69, doi: 10.1016/j. compedu.2014.03.008.

Harnad, S. (2011), "Lunch uncertain (Review of L. Floridi (2011) The Philosophy of Information (Oxford)", Times Literary Supplement, 21 October, No. 5664, pp. 22-23.

Jenkins, H. (2006a), "Henry Jenkins on the new media landscape: rethinking learning", MacArthur Foundation, available at: www.youtube.com/watch?v=INhOB9gWPiA (accessed 26 November 2019).

Jenkins, H. (2006b), Convergence Culture: Where Old and New Media Collide, New York University Press, New York, NY.

Kenway, J. and Bullen, E. (2001), Consuming Children: Education-Entertainment-Advertising, Open University Press, Buckingham.

Livingstone, S.M. and Sefton-Green, J. (2016), The Class Living and Learning in the Digital Age (Connected Youth and Digital Futures), New York University Press, New York, NY.

Long, C. (2004), The Ethics of Ontology: Rethinking an Aristotelian Legacy, State University of New York Press, New York, NY.

Losada, M. and Bailey, D. (2019), "The future of protest is high tech - just look at the Catalan independence movement", The Conversation, 5 November, available at: https://theconversation. $\mathrm{com} /$ thefuture-of-protest-is-high-tech-just-look-at-the-catalan-independence-movement-125776 (accessed 26 November 2019).

Merchant, Z., Goetz, E., Cifuentes, L., Keeney-Kennicutt, W. and Davis, T. (2014), "Effectiveness of virtual reality-based instruction on students learning outcomes in K-12 and higher education: a meta-analysis", Computers \& Education, Vol. 70, pp. 29-40, doi: 10.1016/j.compedu.2013.07.033.

Morrison, N. (2014), "It's time to rethink our use of technology in schools", Forbes Online, 22 October, available at: www.forbes.com/sites/nickmorrison/2014/10/22/its-time-to-rethink-ouruse-of-technology-in-schools/ (accessed 26 November 2019).

Nissenbaum, H. (2010), Privacy in Context: Technology, Policy, and the Integrity of Social Life, Stanford University Press, Palo Alto, CA.

OCT (2011), "Use of electronic communication and social media", Ontario College of Teachers, available at: www.oct.ca/resources/advisories/use-of-electronic-communication-and-social-media

OECD (2015), Students, Computers and Learning Making the Connection, Organisation for Economic Co-operation and Development Publishing, Paris, available at: http://dx.doi.org/10.1787/97892 64239555-en

Ohler, J., Bradley, D., Cabiria, J., Fremlin, J., Morin, C., Neal, M. and Holmes-Smith, Y. (2015), Digital Citizenship in the 21st Century: Volume 7, CreateSpace Independent Publishing Platform. 
Prensky, M. (2001), "Digital natives, digital immigrants", On the Horizon, Vol. 9 No. 5, pp. 1-6, doi: 10.1108/10748120110424816.

Schor, J. (2004), Born to Buy: The Commercialized Child and the New Consumer Culture, Scribner, New York, NY.

Searle, J. (2014), "What your computer can't know”, The New York Review of Books Online, 9 October, available at: www.nybooks.com/articles/archives/2014/oct/09/what-your-computer-cant-know/ (accessed 26 November 2019).

Smith, L. and McMenemy, D. (2017), "Young people's conceptions of political information”, Journal of Documentation, Vol. 73 No. 5, pp. 877-902, available at: https://doi.org/10.1108/JD-03-2017-0041

Ulansey, D. (2000), "Culture transition and spiritual transformation: from Alexander The Great to cyberspace", in Singer, T. (Ed.), The Vision Thing: Myth, Politics, and Psyche in the World, Routledge, London and New York, NY, pp. 213-231.

Vallor, S. (2016), Technology and the Virtues: A Philosophical Guide to a Future Worth Wanting, Oxford University Press, New York, NY.

van Dijk, J. and van Deursen, A. (2014), Digital Skills. Palgrave Macmillan's Digital Education and Learning, Palgrave Macmillan, New York, NY, doi: 10.1057/9781137437037_3.

Wu, H., Lee, S., Chang, H. and Liang, J. (2013), "Current status, opportunities and challenges of augmented reality in education", Computers \& Education, Vol. 62, pp. 41-49, doi: 10.1016/j. compedu.2012.10.024.

\title{
Further reading
}

Ess, C. (2003), "Can Socratic virtue (arête) and Confucius' exemplary person (junzi) be taught online?", Arts and Humanities in Higher Education, Vol. 2 No. 2, pp. 117-137.

Ess, C. (2010a), "Trust and new communications technologies: vicious circles, virtuous circles, possible futures. knowledge", Technology \& Policy, Vol. 23 Nos 3-4, pp. 287-305.

European Commission (2016), "Digital Futures", available at: http://ec.europa.eu/futurium/en/system/ files/ged/futurium_scientific_report_v10revcl_v2_0.pdf (accessed 26 November 2019).

Floridi, L. (2010a), The Cambridge Handbook of Information and Computer Ethics, Cambridge University Press, Cambridge.

Floridi, L. (2014a), The Fourth Revolution: How the Infosphere is Reshaping Human Reality, Oxford University Press, Oxford.

Floridi, L. (2014b), "Luciano Floridi responds to NYROB review of the fourth revolution", Oxford University Press Blog, Oxford University Press, Oxford, available at: http://blog.oup.com/2014/11/lucianofloridi-responds-nyrob/ (accessed 26 November 2019).

Onlife Initiative (2016), The Onlife Manifesto: Being Human in a Hyperconnected Era, European Commission, available at: www.oapen.org/search?identifier=1001971 (accessed 26 November 2019).

Turing, A.M. (1950), “Computing machinery and intelligence”, Mind, Vol. 59 No. 236, pp. 433-460.

\begin{abstract}
About the author
Estelle Clements holds $\mathrm{PhD}$ from the Dublin Institute of Technology. Her research focuses on digital civics. She also holds degrees in the History of Medicine, Education, Classics and Theatre. She has worked as Theatre Director and Teacher and maintains the website digitalcivics.org. Estelle Clements can be contacted at: digitalcivics@gmail.com
\end{abstract}

For instructions on how to order reprints of this article, please visit our website:

www.emeraldgrouppublishing.com/licensing/reprints.htm

Or contact us for further details: permissions@emeraldinsight.com 